\title{
Internal water footprint assessment of Saudi Arabia using the Water footprint Assessment Framework (WAF)
}

\author{
$\underline{\text { S. Multsch }}{ }^{\text {a }}$, Y.A. Alrumaikhani ${ }^{\text {b }}$, O.A. Alharbi ${ }^{\text {b }}$, H.-G. Frede ${ }^{\text {a }}$ and L. Breuer ${ }^{\text {a }}$ \\ a Institute for Landscape Ecology and Resources Management, Justus - Liebig - University Giessen \\ $b$ National Center for Water Research, King Abulaziz City for Science and Technology, Riyadh \\ Email: Sebastian.Multsch@umwelt.uni-giessen.de
}

\begin{abstract}
The largest share of total water resources utilization is required by the agricultural sector with an average of $80 \%$ on the global scale and $90 \%$ in Saudi Arabia. In contrast to rain fed agriculture, water use in Saudi Arabia is directly linked to irrigation as rainfall only contributes to a minor proportion of crop water requirements. Non-renewable fossil aquifers provide the origin of this irrigation water. Reserves are localized at depths between 150 and $1500 \mathrm{~m}$. Furthermore, the salinisation of agriculture fields puts an additional pressure on fresh water resources in Saudi Arabia. Maintaining soil quality generally requires salt leaching for which additional fresh water resources are being used. On a global scale up to $50 \%$ of soils in semi-arid and arid environments are affected by salinization, indicating that the indirect water use for leaching significantly contributes to total water resources use in irrigation based agricultural production systems. We therefore developed the Water footprint Assessment Framework (WAF) for estimating the fate of water use in agricultural production systems. WAF enables the spatial explicit calculation of the internal water footprint of a region or nation, considering all water resources required to produce food and feed, including green (precipitation), blue (irrigation) and grey (de-salinization) water. WAF is based on the virtual water concept originally introduced by Allan in the 1990s, and further developed to the water footprint concept by Hoekstra in the past years. Equipped with a graphical user interface WAF calculates crop water requirement according to the Food and Agricultural Organization FAO56 crop water guidelines. User defined parameters allow to set crop types, irrigation efficiencies, salinity of irrigation water or depression of yields due to salinization. We further implemented the WAF scenario manager to rapidly investigate the effect of introducing different cropping regimes on site specific water resources. The WAF database provides soil and climate information as well as data on yields to calculate crop water requirements for each spatial entity. Apart from using public avaialable data provided by FAO on soils, climate and yields that only allow the estimation of the water footprint of an entire nation, WAF can be spatially adapted to more site specific data by extending the WAF database, as shown in this case study. Here we present results of such a spatially more differentiated approach of estimating the internal water footprint for Saudi Arabia. Using the scenario manager we present how WAF can also be applied to improve the nation's water footprint. Irrigation management and changes in agricultural crops scenarios are presented to show potential improvements of the internal agricultural Saudi Arabian water footprint. The spatially explicit approach facilitates to delineate locations where improvements in the water footprint will allow the most effective reduction of water losses in the country. Average water footprints of cereals, vegetables, fodder crops and fruits are $4725 \mathrm{~m}^{3} \mathrm{t}^{-1}, 761 \mathrm{~m}^{3} \mathrm{t}^{-1}, 1887 \mathrm{~m}^{3} \mathrm{t}^{-1}$ and $4753 \mathrm{~m}^{3} \mathrm{t}^{-}$ ${ }^{1}$, respectively. The surprisingly low water footprint of vegetables can be explained by the high yields and very efficient water resource utilization, despite the generally high total water use for vegetable production. Fodder crops, dominated by Alfalfa production, give high yields as well. Fruits in contrast are dominated by date production, a palm that is relatively inefficient with respect to water use efficiency. In addition it is quite salt sensible and therefore requires large amounts of gray water for leaching soils. The national water footprint of the agriculture sector has been calculated in relation to varying irrigation settings, which refer to salt concentration of the applied irrigation water, irrigation method and yield potential. The mean national water footprint of Saudi Arabia amounts to $23.5 \mathrm{~km}^{3} \mathrm{yr}^{-1}$ (2004-2008) assuming nationwide ineffective sprinkler and surface irrigation with efficiencies of around 50-60\% and average salt concentrations of irrigation water of $4 \mathrm{dS} \mathrm{m}^{-1}$. This estimate by WAF is in good agreement with published values of around $21 \mathrm{~km}^{3} \mathrm{yr}^{-1}$ for the year 2006. However, by increasing irrigation efficiency up to $85 \%$ for example by promoting drip irrigation, and reducing salt concentrations down to $1.2 \mathrm{dS} \mathrm{m}^{-1}$, the internal water footprint of Saudi Arabian agricultural sector could almost be halved to $13.5 \mathrm{~km}^{3} \mathrm{yr}^{-1}$.
\end{abstract}

Keywords: virtual water, water footprint, graphical user interface, FAO56 CropWat, GIS-based 


\section{INTRODUCTION}

\subsection{Agriculture water consumption}

More than $80 \%$ of the global water consumption can be attributed to the agricultural and food sector (Hoekstra and Chapagain, 2008). This fraction is even higher in arid regions, e.g. in Saudi Arabia with 90\%. The reason for this is the high fraction of irrigated agriculture. An efficient utilization of water resources is a key for saving fresh water resources. Wallace (2000) mentioned that the improvement of the water use efficiency is a major factor in future food production, due to the fact that additional arable land is limited. The irrigation systems highly influence the water consumption of agriculture due to the fact that a significant part of agriculture is still irrigated with inefficient, traditional methods like surface irrigation. For example, $66 \%$ of the irrigation systems are under sprinkler irrigation techniques and $34 \%$ under surface irrigation in Saudi Arabia (Frenken, 2009).

In the mid-1990s John Anthony Allan proposed the concept of virtual water to analyse and improve (agricultural) water use. The virtual water content of growing a crop is defined as the water required to generate one unit of biomass (Allan, 1998). Building on these ideas Hoekstra and Hung (2002) introduced the water footprint (WF) which accounts for the direct and indirect freshwater consumption of a consumer or producer, whereby considering the origin of the water. The WF is divided into a green, blue and grey component. Green water refers to precipitation. Blue water includes groundwater and surface water resources that are additionally required to green water and which are applied through irrigation. In case of crop growth, green and blue water are denoted as the waters that contribute to crop growth in the form of transpiration (productive water) or which are evaporated from the soil during the growing season (unproductive water). Grey water defines the amount of water needed to dilute polluted water to water quality levels set by international or national water quality standards. In irrigated agriculture grey water is related to water that is required to leach salts form the rooting zone. The so called leaching requirement plays an important role in such regions. An efficient planning of water resources use is closely connected to the origin and the destiny of available water resources, especially in irrigated agriculture systems. Despite this need, most investigations on WF analyses focus on the country (national) scale, rather than investigating the internal site specific WF of agriculture where the focus of this paper is being put.

\subsection{Current applications}

The FAO56 CropWat model has been widely applied to calculate water fluxes of agricultural systems. The model considers plant growth and soil moisture related processes as well as irrigation practices. In many studies this approach was used in combination with statistical data on biomass production to calculate the WF (e.g. Hoekstra and Chapagain, 2008). Hanasaki et al. (2010) used the global water resource model H08model to calculate virtual water fluxes of agriculture products with respect to green and blue water. Liu et al. (2007) provide the GEPIC model, a GIS-based version of the EPIC model to also estimate the green and blue water use in cropland and biomass production. In another study, Schuol et al. (2008) estimate spatial explicit green and blue water use for the African continent with the Soil and Water Assessment Tool (SWAT) coupled to the ArcSWAT interface.

Many studies exist which provide maps and data tables for crop water consumption, but the underlying fundamental models are not available for public utilization or only for scientific use. Other authors offer their models in combination with GIS-based user interfaces, but these interfaces often require a high expert knowledge. The usefulness of geo-spatial interfaces, which can be even used by non (or semi-)experts, has also been proposed by Renschler (2003). We conclude that a new model needs a:

- GIS-based graphical user interface (GUI), which is usable by non-GIS experts,

- $\quad$ scenario manager that enables a step by step calculation of alternative scenarios,

- leaching requirement estimator to assess the grey water footprint.

The following sections describe the new development of a simple, straightforward water footprint accounting system with a special emphasis on grey water consideration. After a general introduction to the model set up we present results of the WF accounting for crop production in Saudi Arabia, followed by scenario analyses to develop potential improvements of water resources utilization in the country. 


\section{WATER FOOTPRINT ASSESSMENT FRAMEWORK (WAF)}

\subsection{Model set up}

The Water footprint Assessment Framework (WAF) is a spatial decision support system for agricultural water footprint calculations, which accounts for regional climatic and soil dependent conditions as well as for irrigation practices. WAF is divided into four components (Figure 1).

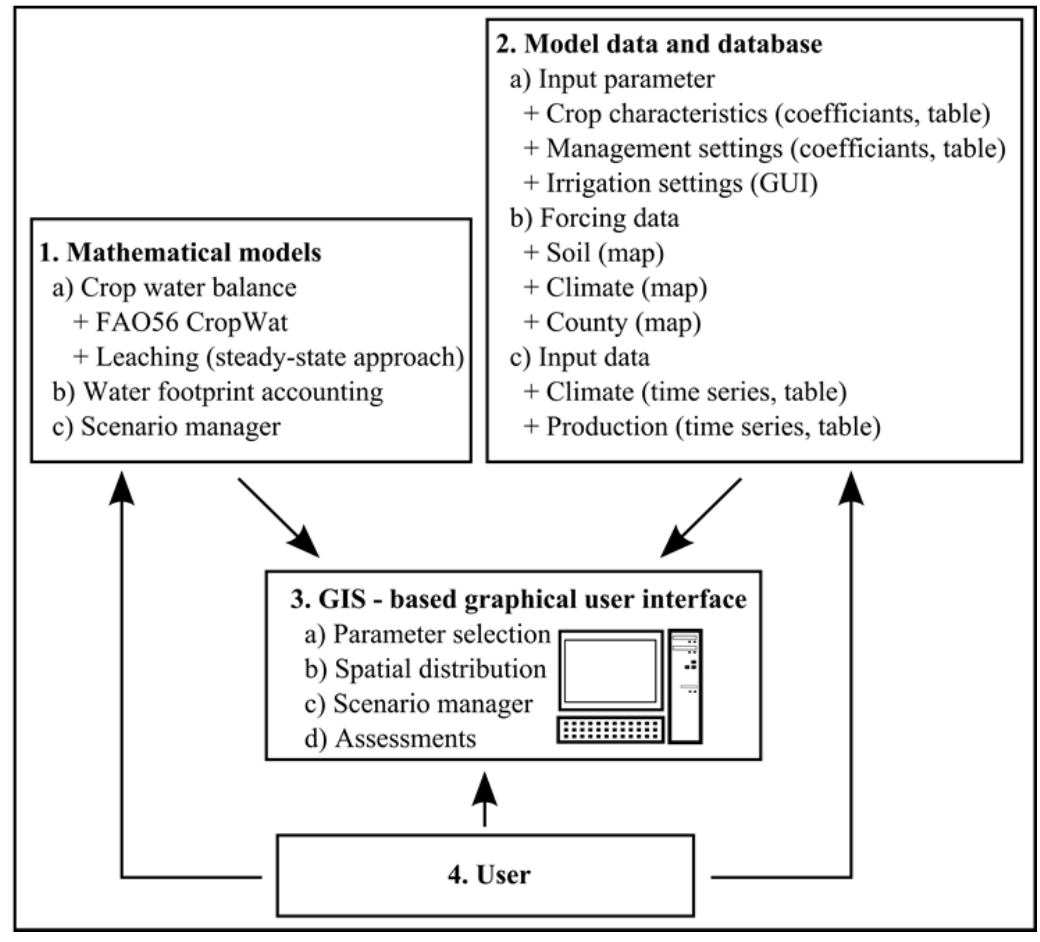

Figure 1. Flowchart of the Water footprint Assessment Framework $(\mathrm{WAF}) . \mathrm{GUI}=$ Graphical User Interface

The first component, i.e. the mathematical model, simulates the water fluxes of a growing crop and balances the water use of the system. Water fluxes are calculated using the FAO56 CropWat approach (Allen et al., 1998). Leaching requirements are calculated according to Ayers and Westcot (1989). Hence, the water use of regions equals the water footprint within a nation from Hoekstra et al. (2011).

The second component corresponds to the database that contains model forcing data and input parameters. The spatial distribution of soil parameters and climate regions is given by vector maps. Crop yields, harvest area and climate data are provided as time series.

The third component is the graphical user interface (GUI). Due to the fact that the target operating system is Microsoft Windows, the tool has been developed within the Microsoft Visual Studio with Visual Basic.NET. The second reason for this choice is the interface of Visual Studio to geographic information systems like ArcGis (ESRI) and other spatial libraries like MapWinGis.

The fourth component is the user. Through the GUI the user selects commodities (arable crops), locations and the time period (years). In the next steps the user picks the irrigation practice, irrigation efficiency and the salinity of the applied irrigation water. After making these general settings the user can define alternative production scenarios within the scenario manager.

\subsection{Calculation steps}

The water footprint of an area $\left(\mathrm{WF}_{\text {area }}\right)$ is calculated from the water footprint of growing a crop ( $\left.\mathrm{WF}_{\text {crop }}\right)$ and the related production quantity (Prod) of all crops (x) produced in a specific area. Prod is calculated from the crop yield (Y) times the harvest area (HA) of the crop. $\mathrm{WF}_{\text {area }}$ is calculated with equation 1 :

$W F_{\text {area }}=\sum_{x} W F_{\text {crop }}(x) \cdot \operatorname{Prod}(x)$

with $\mathrm{WF}_{\text {area }}$ in $\left[\mathrm{km}^{3} \mathrm{yr}^{-1}\right], \mathrm{WF}_{\text {crop }}$ in $\left[\mathrm{m}^{3} \mathrm{t}^{-1}\right]$ and Prod in $\left[\mathrm{t} \mathrm{yr}^{-1}\right]$. The water footprint of a single crop is divided into a green $\left(\mathrm{WF}_{\mathrm{g}}\right)$, blue $\left(\mathrm{WF}_{\mathrm{b}}\right)$ and grey $\left(\mathrm{WF}_{\mathrm{gr}}\right)$ component. The first components are derived from the crop water balance calculated with the FAO56 CropWat model. The estimation includes the calculation of effective precipitation $\left(\mathrm{P}_{\text {eff }}\right)$, potential evapotranspiration, crop specific evapotranspiration $\left(\mathrm{ET}_{\mathrm{c}}\right)$ and irrigation $\left(\mathrm{I}_{\mathrm{rr}}\right)$. Leaching requirement $(\mathrm{LR})$ is calculated with a steady state model proposed by Ayers and Westcot (1989).

The three components are then added according to equation 2 : 
$W F_{\text {crop }}=\overbrace{\frac{\min \left(E T_{c}, P_{\text {eff }}\right)}{Y}}^{W F_{g}}+\overbrace{\frac{I r r}{Y}}^{W F_{b}}+\overbrace{\frac{L R}{Y}}^{W F_{g r}}$

with $\mathrm{WF}_{\text {crop }}$ in $\left[\mathrm{m}^{3} \mathrm{t}^{-1}\right], \mathrm{ET}_{\mathrm{c}}, \mathrm{P}_{\text {eff }}, \mathrm{I}_{\mathrm{rr}}$ and LR in $\left[\mathrm{m}^{3} \mathrm{ha}^{-1}\right]$ and $\mathrm{Y}$ in $\left[\mathrm{tha}^{-1}\right]$.

\section{QUANTIFYING THE WATER FOOTPRINT OF SAUDI ARABIA}

The Kingdom of Saudi Arabia is the largest country on the Arabian Peninsula with a total area of 2.15 million $\mathrm{km}^{2}$ and 24.6 million inhabitants. The cultivable area is 52.7 million ha, whereby 1.01 million ha are currently used (Frenken, 2009). The Kingdom is divided into thirteen emirates and the capital city is Riyadh, which is located in the middle of the country. Agriculture production, industry and households consume $90 \%, 9 \%$ and $1 \%$ of water resources in the country, respectively.

\subsection{Environmental conditions}

Saudi Arabia is characterized by annual average rainfall between 40 and 140 $\mathrm{mm}$, with the exception of the Oman Mountains in the Eastern Province and the Asir Mountains (SW), where the

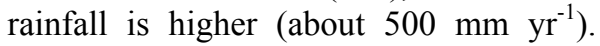
The reference evapotranspiration $\left(\mathrm{ET}_{\mathrm{o}}\right)$ ranges from $2500(\mathrm{NW}$, western coast

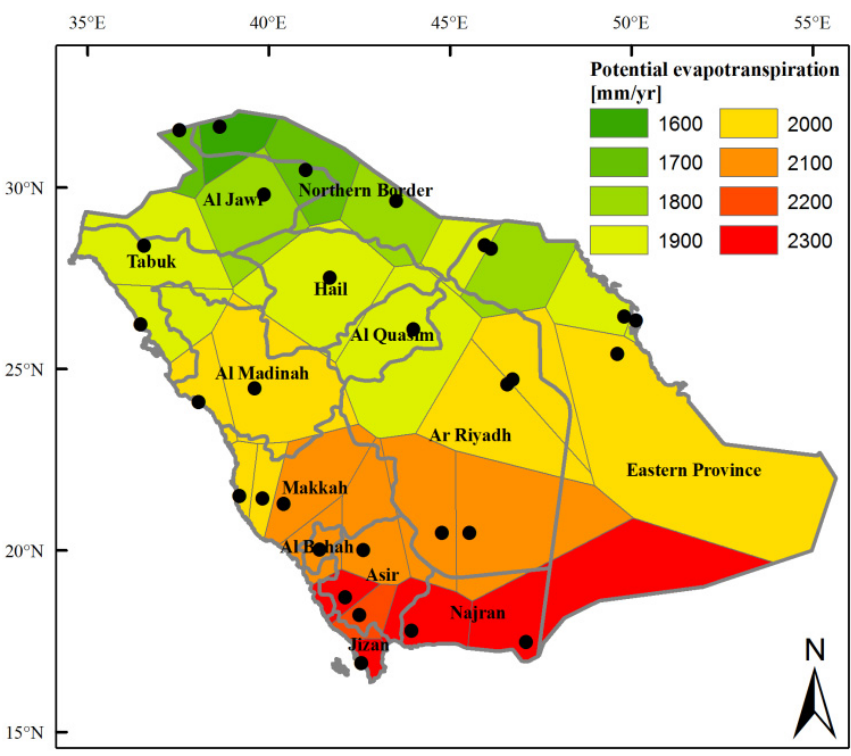

Figure 2. Potential evapotranspiration in Saudi Arabia derived from 30 climate station (data source: PME, 2010a).

line) to $4500 \mathrm{~mm} \mathrm{yr}^{-1}$ in the Saudi Arabian desert (Al-Rashed and Sherif, 2000). Own calculations with data from the (PME, Presidency of Meteorology and Environment 2010a) indicate an annual mean potential evapotranspiration between 1600 and $2300 \mathrm{~mm} \mathrm{yr}^{-1}$ (Figure 2). The highest evapotranspiration rates occur in the SE of Saudi Arabia, while lowest rates up to $1600 \mathrm{~mm} \mathrm{yr}^{-1}$ are observed in Tabuk, Asir and Jizan.

Groundwater resources are important and water is taken mainly from fossil groundwater storages. The annual recharge of Saudi Arabian aquifers is estimated to be $1.28 \mathrm{~km}^{3}$, whereby $0.39 \mathrm{~km}^{3}$ flow from these aquifers to neighbouring nations. The total groundwater reserves are estimated to $500 \mathrm{~km}^{3}$, whereby a fraction of $340 \mathrm{~km}^{3}$ is economical extractable (Frenken, 2009).

\subsection{Crop production}

The crop production of the thirteen emirates of Saudi Arabia is $9.73 \mathrm{Mt}$ in 2008 (Figure 3) (PME, Presidency of Meteorology and Environment 2010b). The major part of the production is located in Ar Riyadh (33\%), Al Jawf (13\%), Al Quasim (11\%) and Hail (11\%). Crop production is divided into cereals,

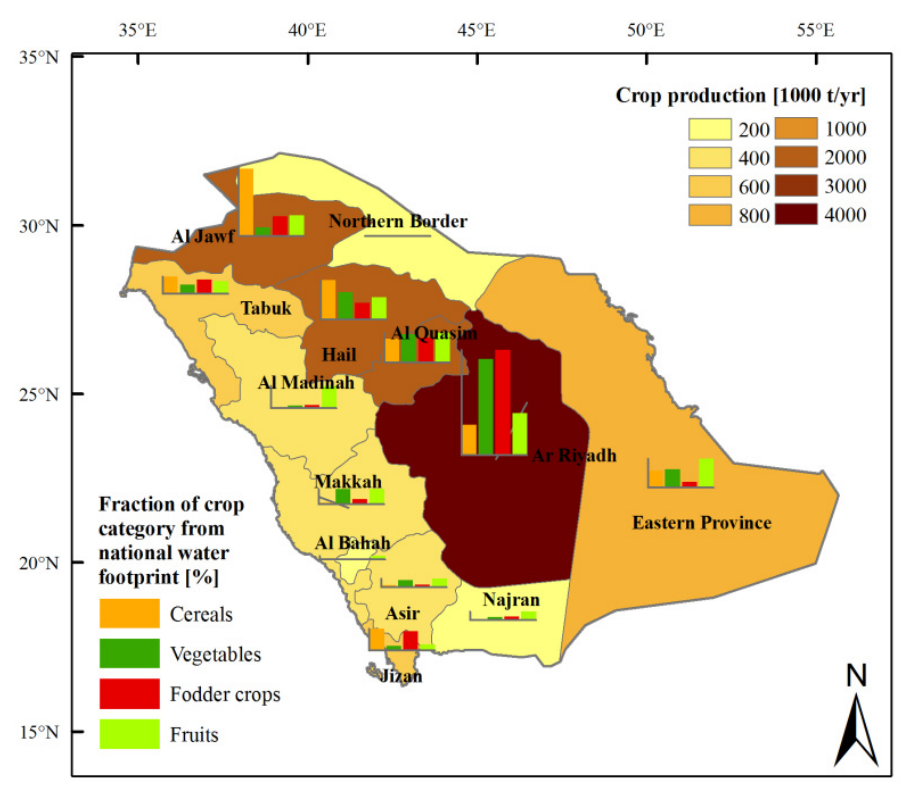

Figure 3. Crop production in 2008. Bars indicate fraction of crop categories within each emirate (data source: PME, 2010b). 
vegetables, fodder crops and fruits. Arround one third of cereals is produced in Al Jawf and and 18\% in Hail. The centre for production of vegetables (44\%) and fodder crops (58\%) is Ar Riyadh. High amount of fruits are produced in Ar Riyadh (19\%), Al Quasim (13\%) and Eastern province (14\%). Cereals production is dominated by wheat (86\%). Major vegetables include tomatoes and potatoes (19 and 17\%). Fodder crops are dominated by Alfalfa (67\%) and fruits by date palms (63\%).

\subsection{Water footprint of crop production}

Agriculture products are divided into four crop categories, i.e. cereals, vegetables, fodder crops and fruits, which contribute $47,5,19$ and $29 \%$ to the national water footprint $W_{\text {area }}$ of $25 \mathrm{~km}^{3}$ for agriculture production. Average water footprints of cereals, vegetables, fodder crops and fruits $\left(\mathrm{WF}_{\text {crop }}\right)$ are $4725 \mathrm{~m}^{3} \mathrm{t}^{-1}$, $761 \mathrm{~m}^{3} \mathrm{t}^{-1}, 1887 \mathrm{~m}^{3} \mathrm{t}^{-1}$ and $4753 \mathrm{~m}^{3} \mathrm{t}^{-1}$, respectively. In general, the water footprint of growing crops in Saudi Arabia can be summarized as follows:

- Cereals and fruits have the highest water footprint, whereby cereals are dominated by wheat $(86 \%$ of total cereal production) and fruits by dates (60\% of total fruit production).

- Vegetables and fodder crops have generally lower water footprints, because of high yields.

- Tomatoes and potatoes contribute a high fraction to total vegetable production and have very low water footprints.

- Total water consumption of vegetables and fodder crops is higher compared to cereals and fruits.

Water footprints of single crops are the basis of the regional and annual water balance calculation. The $25 \mathrm{~km}^{3} \mathrm{WF}_{\text {area }}$ in 2008 for Saudi Arabia is in agreement with other values published elsewhere. Hussain et al. (2010) estimated the agriculture water consumption to $14.5 \mathrm{~km}^{3}$ in 1996 with a corresponding total harvest area estimated to 1,024,627 ha. Frenken (2009) calculated irrigation water use of $6.8 \mathrm{~km}^{3}$ (1980) to $21 \mathrm{~km}^{3}$ (2006) with a corresponding harvested and irrigated cropping area in 2006 of 1,213,587 ha. Plotting WF over time leads to a significant linear increase that is most likely related to similar increases in harvested area.

In comparison to the literature data, the water footprint looks at the consumption perspective of agriculture crops and therefore includes in addition to irrigation water the rainfall, which contributes to crop growth. A higher salinity leads to a higher demand of grey water, to leach out

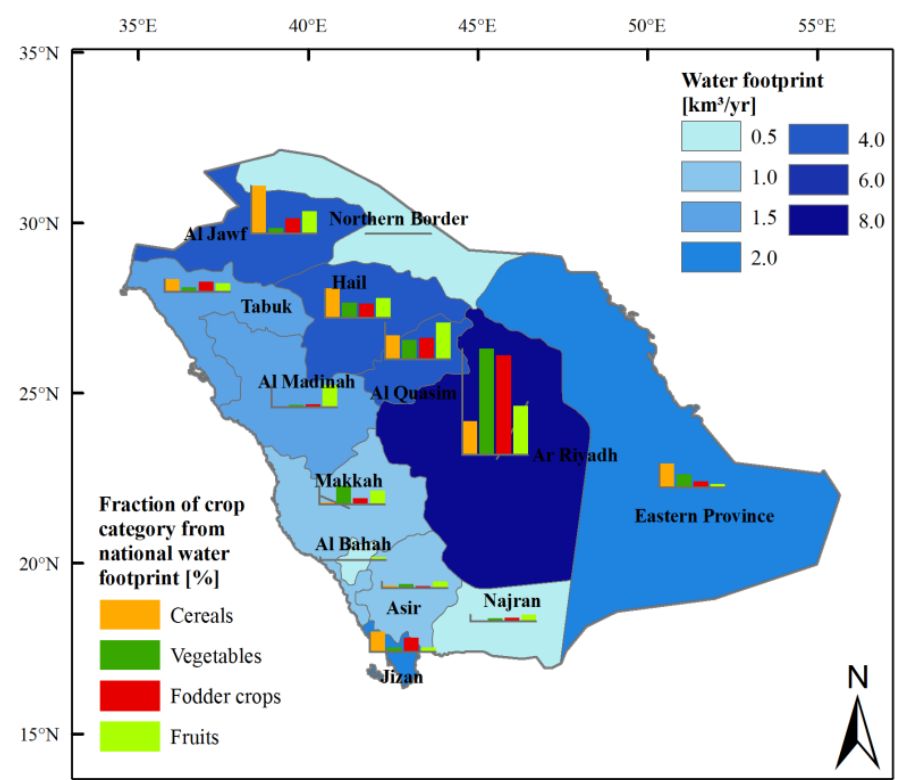

Figure 4. Water footprint of crop production in Saudi Arabia in 2008 (see Baseline scenario Table 1). Note that for emirates with a $\mathrm{WF}_{\text {area }}<0.5 \mathrm{~km}^{3}$ (Al Baha, Northern Border) no differences between crop categories can be depicted.

salts from the rooting zone. The fraction of green, blue and grey water is $3 \%, 76 \%$ and $21 \%$ in the baseline scenario at the national scale. The emirate Jizan has with $7 \%$ the highest fraction of green water. The fraction of blue water varies between $66 \%$ (Northern Border) and $81 \%$ (Eastern Province, whereby these emirates contribute only a minor part to the national $\mathrm{WF}_{\text {area }}$. The blue water fraction in the emirates with an $\mathrm{WF}_{\text {area }}$ over $4.0 \mathrm{~km}^{3} \mathrm{yr}^{-1}$ varies between $73 \%$ and $79 \%$. The highest grey water fraction can be observed in Northern Border (32\%), Najran (26\%) and Ar Riyadh (24\%), whereby these emirates have high fractions of fodder crops or fruits.

On the regional scale, the emirates Ar Riyadh, Al Jawf, Hail and Al Quasim contribute 70\% to the national water footprint. The bar charts in Figure 4 indicate the fraction of the water footprint of each emirate from the national water footprint per crop category. Ar Riyadh has the highest WF for fodder crop and vegetables and contributes over $50 \%$ to the national $\mathrm{WF}_{\text {area }}$ of these crop categories. With $25 \%$ Ar Riyadh also has the largest share of $\mathrm{WF}_{\text {fruits }}$. The second most important emirate after Ar Riyadh for the $\mathrm{WF}_{\text {area }}$ of crop production is $\mathrm{Al}$ Quasim with a share of 11,10 and 19\% for fodder crops, vegetables and fruits, respectively. 


\section{IMPROVING THE AGRICULTURE WATER FOOTPRINT}

Apart from estimating the water footprint of agricultural production WAF can also be used to develop alternative management as well as cropping scenarios or to evaluate the effect of agricultural policies on water resources (e.g. subsidisation or ban of specific crops). In the following section we present a set of water consumption scenarios and corresponding crop production WFs. Furthermore we investigate the effect of different salt concentrations in irrigation water with a focus on the effects on $\mathrm{WF}_{\text {grey }}$. Low salt concentrations in the soil enable higher yields, but fresh water has to be applied for desalination of soils to achieve these target concentrations.

Table 1. Scenarios with varying irrigation settings.

\begin{tabular}{ccccc} 
Scenario & Irrigation method & Irrigation efficiencv & Yield potential $[\%]$ & Salinity $\left[d S \mathrm{~m}^{-1}\right]$ \\
\hline Baseline & Surface irrigation & 55 & 100 & 2.5 \\
\hline I & Surface irrigation & 55 & 100 & 1.2 \\
\hline II & Sprinkler irrigation & 70 & 100 & 1.2 \\
\hline III & Drip irrigation & 85 & 100 & 1.2 \\
\hline IV & Surface irrigation & 55 & 80 & 1.2 \\
\hline V & Surface irrigation & 55 & 80 & 2.5 \\
\hline VI & Surface irrigation & 55 & Crop dependent & 8.0 \\
VII & Surface irrigation & 55 & & 80 \\
\hline
\end{tabular}

${ }^{1}$ Yield potential is reduced of dates $(94 \%)$, fodder crops $(74 \%)$, carrots $(72 \%)$, cucumber $(72 \%)$, onion (72\%), eggplant (72\%), melon (72\%), okra (72\%), squash $(72 \%)$, vegetable crop $(72 \%)$, water melon $(72 \%)$, tomato $(70 \%)$, grapes $(60 \%)$, potato $(53 \%)$, maize $(50 \%)$, citrus $(38 \%)$, other fruits $(38 \%)$.

Table 1 illustrates the four parameters which are modified: irrigation method, irrigation efficiency, yield potential and salinity. Scenarios I to III deal with variations in the irrigation method and efficiency whilst yield potential and salinity remain at the same level. Yield potential is decreased to $80 \%$ and salinity increases stepwise from 1.2 to $4.0 \mathrm{dS} \mathrm{m}^{-1}$ in Scenario IV to VI. As mentioned before, the average salinity of the aquifers vary between 2 to over $8 \mathrm{dS} \mathrm{m}^{-1}$ on the Arabian Peninsula. The last scenario looks at the WF with the highest salinity set to $8 \mathrm{dS} \mathrm{m}^{-1}$ and a yield potential of $100 \%$, but with one restriction: yields of salt sensible crops are decreased, because salt conditions do not allow 100\% yield. Here, WAF calculates the possible yield potential for each crop under the given salt concentration.

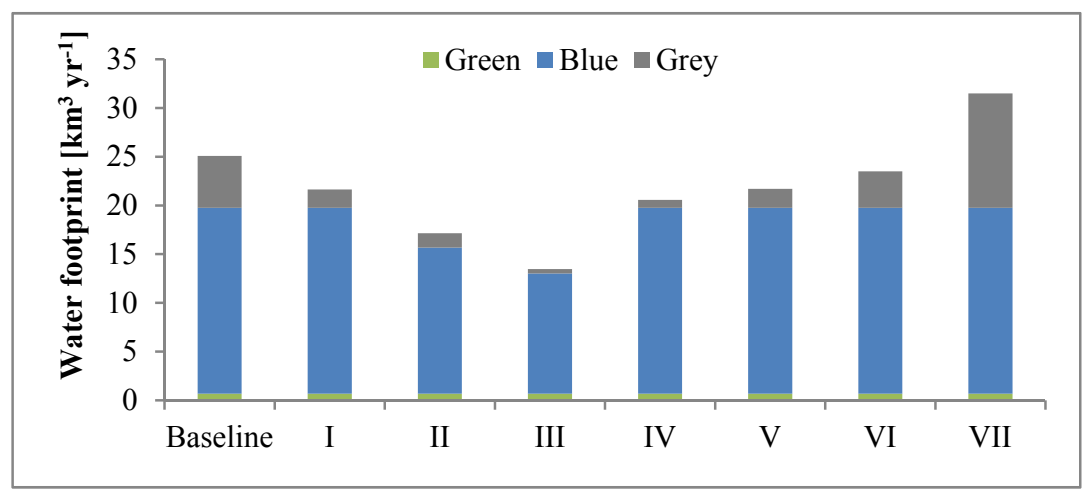

Figure 5. National $\mathrm{WF}_{\text {area }}$ of seven alternative irrigation scenarios and the baseline scenario.
Figure 5 illustrates the WF in relation to the seven scenarios for the year 2008. WF varies between $13.5 \mathrm{yr}^{-1}$ (III) and $31.5 \mathrm{~km}^{3} \mathrm{yr}^{-1}(\mathrm{VII})$. The WF increases from $13.5 \mathrm{~km}^{3} \mathrm{yr}^{-1}$ with drip to $17.1 \mathrm{~km}^{3} \mathrm{yr}^{-1}$ with sprinkler and $21.6 \mathrm{~km}^{3} \mathrm{yr}^{-1}$ with surface irrigation. The WF decreases in scenario IV in comparison to III because of the lower yield potential and the related lower leaching requirement. As this lower water consumption comes

along with lower yields, the net effect on the WF is almost negligible. The WF increases in scenario V and VI are due to the higher leaching requirement and the resulting increase in $\mathrm{WF}_{\text {grey }}$, contributing $9 \%(\mathrm{~V})$ and $15 \%$ (VI). Scenario VII differs from the other simulations, as the yield potential varies with crop types (Table 1). In this case $\mathrm{WF}_{\text {grey }}$ contributes $37 \%$ to the national $\mathrm{WF}_{\text {area }}$. This high demand can be lead back to the high salt concentration and the subsequently needed water for desalination of soils.

Water savings could also be realized through the use of saline irrigation water and by accepting lower yield potentials. This fact is shown in the differences of scenarios I and V. Nevertheless, highest improvements of WFs can be realized by increasing the efficiency of irrigation techniques. For example, improving extensive crop production by changing from surface to sprinkler irrigation as indicated in scenario II is a promising strategy for increasing the WF in Saudi Arabia. 


\section{CONCLUSIONS}

WAF is helpful tool to analyse the water footprint of agricultural production and to develop country wide scenarios for a better water resources management. The tool considers the effect of growing salt tolerant crops and improving irrigation techniques to realize water savings in the agriculture sector of Saudi Arabia. While most water resource estimations for irrigation areas exclude the amount needed to desalinize soils WAF is equipped with a leaching calculator to consider the required grey water component to meet local or national water quality standards. However, the currently implemented leaching calculator is a fairly simple empirical method. The implementation of a dynamic salt model likely increases the model's accuracy through the explicit consideration of salt storage in the soil. It would be interesting to test a variety of leaching calculators to see the uncertainty behind this component of the water footprint.

One major aspect while developing WAF was to finally provide a straightforward and easy-to-use system for non GIS-experts. Based on the step by step calculations of the water footprint and the possibility to develop and define management and production scenarios on-the-fly and during run-time increase the model's practicability. Whether this practicability will be achieved will be tested in a set of training and stakeholder participation courses to be held at the end of 2011 in Saudi Arabia.

Given the flexible set up of the tool other regions with a strong irrigation component and salinity problem should be included in WAF to test the model's transferability. The model should also be extensively tested and validated within smaller scales and with higher spatial and temporal resolution data. Hence, in a next step WAF will be set up for the Murray Darling River basin in Australia, where a wealth of spatial data is at hand.

\section{ACKNOWLEDGEMENT}

This work is applied in a joint research project from the Justus-Liebig-University Giessen - JLU (Germany) and the King Abulaziz City for Science and Technology - KACST (Riyadh, Kingdom of Saudi Arabia) and is mainly funded by KACST.

\section{REFERENCES}

Allan, J. A. (1998). Virtual water: A strategic resource global solutions to regional deficits. Ground Water, 36(4), 545-546.

Allen, R. G., Pereira, L. S., Raes, D., and Smith, M. (1998). Crop evapotranspiration-Guidelines for computing crop water requirements. FAO Irrigation and Drainage Paper 56, Rome, Italy.

Al-Rashed, M. F., and Sherif, M. M. (2000). Water resources in the GCC countries: an overview. Water resources management, 14(1), 59-75.

Ayers, R. S., and Westcot, D. W. (1989). Water quality for agriculture. FAO Irrigation and Drainage Paper 29, Rev. 1, Rome, Italy.

Frenken, K. (2009). Irrigation in the Middle East region in figures. AQUASTAT Survey - 2008. FAO Water Reports, 34, $402 \mathrm{pp}$.

Hanasaki, N., Inuzuka, T., Kanae, S., and Oki, T. (2010). An estimation of global virtual water flow and sources of water withdrawal for major crops and livestock products using a global hydrological model. Journal of Hydrology, 384(3-4), 232-244.

Hoekstra, A. Y., and Hung, P. Q. (2002). Virtual water trade: A quantification of virtual water flows between nations in relation to international crop trade. Value of Water Research Report Series, 11, 66 pp.

Hoekstra, A. Y., Chapagain, A. K., and Aldaya, M. M. (2011). The Water Footprint Assessment Manual. Earthscan, London.

Hoekstra, A. Y., and Chapagain, A. K. (2008). Globalization of water: sharing the planet's freshwater resources. Blackwell Publishing, Oxford.

Hussain, G., Alquwaizany, A., and Al-Zarah, A. (2010). Guidelines for Irrigation Water Quality and Water Management in The Kingdom of Saudi Arabia: An Overview. Journal of Applied Sciences, 10(2), 79-96.

Liu, J., Williams, J. R., Zehnder, A. J. B., and Yang, H. (2007). GEPIC-modelling wheat yield and crop water productivity with high resolution on a global scale. Agricultural Systems, 94(2), 478-493.

PME, Presidency of Meteorology and Environment. (2010a). Meteorological data 1985 - 2005. Riyadh.

PME, Presidency of Meteorology and Environment. (2010b). Crop production 2004 - 2008. Riyadh.

Renschler, C. S. (2003). Designing geo spatial interfaces to scale process models: The GeoWEPP approach. Hydrological Processes, 17(5), 1005-1017.

Schuol, J., Abbaspour, K. C., Yang, H., Srinivasan, R., and Zehnder, A. J. B. (2008). Modeling blue and green water availability in Africa. Water Resource Research, W07406. doi:10.1029/2007WR006609.

Wallace, J. S. (2000). Increasing agricultural water use efficiency to meet future food production. Agriculture, Ecosystems \& Environment, 82(1-3), 105-119. 